\title{
Effect of Thumb Spica Splint in de Quervain's Disease
}

Fahad Islam ${ }^{1 *}$, Md. Imam Shahriar², A. B. M Zafar Sadeque ${ }^{3}$, Md. Mahfuzur Rahman ${ }^{4}$, Mohammad Ilias ${ }^{5}$

${ }^{1}$ Assistant Professor, Department of Physical Medicine and Rehabilitation, BGC Trust Medical College and Hospital, Chattogram, Bangladesh

${ }^{2}$ Consultant, Department of Physical Medicine \& Rehabilitation, Chattogram Medical College Hospital, Chattogram, Bangladesh

${ }^{3}$ Assistant Professor, Department of Physical Medicine \& Rehabilitation, Shaheed Sheikh Abu Naser Specialized Hospital, Khulna, Bangladesh

${ }^{4}$ Consultant, Department of Physical Medicine \& Rehabilitation, Parkview Hospital Pvt. Ltd., Chattogram, Bangladesh

${ }^{5}$ Associate Professor \& Head, Department of Physical Medicine, BBMH, Institute of Applied Health Sciences (USTC), Chattogram, Bangladesh

DOI: $10.36347 /$ sjams.2020.v08i10.023

| Received: 02.10.2020 | Accepted: 14.10.2020 | Published: 21.10.2020

*Corresponding author: Fahad Islam

Abstract

Original Research Article

Background: de Quervain's disease has been described as an entrapment of the extensor pollicis brevis and abductor pollicis longus tendons in the first dorsal compartment of the wrist is a common cause of wrist and hand pain. Treatment of the disease consist of pharmacological \& non-pharmacological. The non-Pharmacological includes immobilization, therapeutic heat and cold, electrical nerve stimulator, thumb stabilizer splint, postural correction at work and the adjustment of tools and equipment. The medication included non-steroidal Anti-inflammatory Drugs (NSAIDs) and analgesic, an injection of a steroid mixed with xylocaine into tendon sheaths. Objective: Main goal of this study is to evaluate the effect of Thumb spica splint in the management of de Quervain disease. Methods: This randomized clinical trial was performed in the Department of Physical Medicine and Rehabilitation, Chittagong Medical College Hospital, over a period of six months. Study population were the patients of de Quervain's disease attending the out- patient department of Physical Medicine and Rehabilitation during the study period. Meticulous history taking, clinical examination and relevant investigations were done. Samples was selected by consecutive sampling from the population who are eligible as per inclusion and exclusion criteria from a definite date till desired sample size is reached and eligible participants were allocated into two groups, group A-experimental or interventional group and group B-control group by randomization with the help of lottery. Experimental group was managed by activities of daily living (ADLs) instructions, non-steroidal anti-inflammatory agents (NSAIDs), ultrasound therapy (UST), along with Thumb spica splint. Control group received previous management except Thumb spica splint. Here Tynor brand Thumb spica splint was advised to use to all patient in experimental group, same analgesic drugs Tab. Naproxen $250 \mathrm{mg}$ two times daily after meal was given to all patients along with proton pump inhibitors till acute condition was subside and all patients receive therapeutic ultrasound in a same dosage $(1 \mathrm{watt} / \mathrm{cm} / \mathrm{min}) \mathrm{for} 5$ 10 minutes. So, there were six follow up visits and these evaluations were performed by the same investigator. In each visit, measurement of pain intensity and disability level were performed by using visual analogue scale (VAS), Tenderness Index and Patient rated wrist evaluation (PRWE) respectively. Results: There were 92.7\% patients who had localized pain and only $7.3 \%$ had radiation. Most of the pain in the evening $(56.4 \%)$ and rest had pain at night (43.6\%). Most of the patients in both groups had constant and intermittent type of pain (47.5\% and 45.5\%) other types were sharp and dull. All patients in both groups had some aggravating factor but relieving factors were less $(45.45 \%)$. Significant difference between Group A and Group B was found at week 5 and Week 6 follow up $(\mathrm{P}<0.05)$ whereas other early follow up was non-significant in VAS analysis(p>0.05). Significant difference between Group A and Group B was found at week 4, week 5 and week 6 follow up $(\mathrm{P}<0.05)$ regarding change of tender index in Group A then Group B. No significant difference between Group A and Group B was found at different weeks of follow up (P>0.05) regarding PRWE. Conclusions: Regarding treatment of de Quervain's tenosynovitis, present study shown that use of Thumb spica splint reduce the morbidity and relief of pain of patients when used along with other conventional treatment.

Keywords: de Quervain, meticulous, analgesic, thumb spica splint.

Copyright $\odot 2020$ The Author(s): This is an open-access article distributed under the terms of the Creative Commons Attribution 4.0 International License (CC BY-NC 4.0) which permits unrestricted use, distribution, and reproduction in any medium for non-commercial use provided the original author and source are credited.

\section{INTRODUCTION}

de Quervain's disease is a stenosing tenosynovitis of common tendon sheath of abductor pollicis longus and extensor pollicis brevis muscles [1]. These musculotendinous units control the position and orientation, force application and joint stability of the thumb. The impaired gliding is believed to the result of 
thickening of extensor retinaculum at the first dorsal (extensor) compartment of the wrist, with subsequent narrowing at the fibro-osseus canal [2].

Fritz de Quervain, a Swiss physician, is given credit for first describing this condition with a report of five cases in 1895 and eight additional cases in 1912 [3, 4]. This condition remains the third most reported tendinopathy of the upper extremity in physical workers and it is promoted by diabetes or rheumatoid arthritis [5]. It affects women 8 to 10 times more often than men. Most people who have de Quervain's disease are women between the age of 30-50 years. There is no race predilection exists for de Quervain's tenosynovitis. Many women suffer from de Quervain's tenosynovitis during pregnancy or the postpartum period [6].

The cause of de Quervain's disease is not known [7]. Various repetitive pronation and supination movements of the forearm, ulnar and radial deviation of the wrist and abduction/extension of the thumb have been described as movements that create stress on tendons passing through the extensor retinaculum [8].

People can get de Quervain's disease when they hurt or use the thumb or wrist too much. such as carpenters, office workers ,type writer, gardening, skiing, knitting, using a computer keyboard, wringing out of wet clothes and musician. Some claim that this diagnosis should be included among overuse injuries and that repetitive movements of the thumb are a contributing factor, but there are no scientific data that support a link between hand use and de Quervain's disease [7].

de Quervain's is a clinical diagnosis [9]. No laboratory studies support the diagnosis of de Quervain tenosynovitis. The clinician may consider serologic testing for rheumatoid arthritis (ie, checking serum rheumatoid factor) if the patients has no history of either acute or repetitive trauma or other risk factors [6]. Radiographically, there is usually no changes, although it sometimes can be spotted periosteal reaction [1]. On occasionally evidence of calcification in the tendon or tendon sheath can be noted on x-ray examinations [11].

Activity modification is often the most important consideration in conservative management [9]. Treatment of the disease consist of pharmacological\& non-pharmacological. The nonPharmacological includes immobilization, therapeutic heat and cold, electrical nerve stimulator, thumb stabilizer splint, postural correction at work and the adjustment of tools and equipment [10]. The medication included non-steroidal Anti-inflammatory Drugs (NSAIDs) and analgesic, an injection of a steroid mixed with xylocaine into tendon sheaths.

A thumb spica splint is used to immobilize the first dorsal compartment tendons with a commercially available splint or, depending on patients comfort, a custom molded Orthoplast device [12]. The patient wears the splint during the day for 2 weeks and at night until the next office visit, generally at 6 to 8 weeks. splinting may continue longer, depending on response to treatment [12].

Many patient of de Quervain's disease is diagnosed in Physical Medicine\& Rehabilitation department out-door at Chittagong Medical College\& Hospital. But there is no availability of research document or data in our country that we can estimate its incidence \& Prevalence. In this study an attempt has been focused to see the effects of Thumb spica splint in the treatment of de Quervain's disease and their outcome.

\section{OBJECTIVE \\ General Objective}

- To evaluate the effect of Thumb spica splint in the management of de Quervain disease.

\section{Specific Objective:}

- To measure and compare the improvement of pain in patients with de Quervains disease.

\section{Methodology}

Study type: It was a Randomized controlled trial study.

Study place: Department of Physical Medicine\& Rehabilitation, Chittagong Medical College Hospital (CMCH), Chittagong.

Study period: The duration of the study was 6 (Six) months

Study population: Patient with de Quervain's disease attending out patient Department of Physical Medicine \& Rehabilitation, $\mathrm{CMCH}$; during the study period

Sampling technique: Consecutive sampling

\section{Selection Criteria}

\section{Inclusion Criteria}

The patients having pain and/or swelling over the radial side of the wrist, difficulty in gripping, with positive Finkelstein test.

- Age of the patient should be $\geq 30$ years and $\leq 50$ years

\section{Exclusion Criteria}

- Patients who have pain and/or swelling at the base of the thumb due to fracture of the styloid process of radius (Radiological findings)

- Presence of any contraindication for application of Thumb Spica splint like complicated fractures, open fractures and injuries associated with neurovascular compromise. 
- Patients with OA first carpometacarpal joint.

- Presence of skin lesions

- Inability or unwillingness to discontinue current treatment.

- Pregnancy

\section{Procedure and Data Collection}

After clearance from the Ethical committee of $\mathrm{CMCH}$, patient with wrist pain attending the outpatient department of Physical Medicine \& Rehabilitation $\mathrm{CMCH}$, were registered as population for the study. A thorough history was taken from the registered patients and clinical examination of the patients was done which includes general examination, musculoskeletal and neurological examination of upper limbs, examination of cervical region and wrist joint to find out the cause of wrist pain. Past history of illness and any systemic diseases was inquired cautiously. Patient who met exclusion criteria were excluded all symptoms and signs of each participants were recorded accordingly and clinical diagnosis was made. Relevant investigation was done. Thus diagnosis of de Quervain's disease was confirmed clinically after exclusion of other possible diagnosis by related investigation. Patient other than de Quervain's disease were exempted after providing necessary treatment. Sample was selected by consecutive sampling from eligible participants.

\section{Statistical Analysis}

Data were analyzed and presented in charts and figures by using SPSS (statistical package for the social science) 20 version. Level of significance were assessed with the help of unpaired t-test. All results were expressed as means and standard deviations. A p value below 0.05 was considered to indicate statistical significance.

\section{RESULTS}

Gender distribution of the patients: Regarding analysis of gender in both groups male and female were matched ( $p>0.05)$ and female to male ratio was 2.43:1.

Table-1: Gender distribution of study patients

\begin{tabular}{|l|l|l|l|l|}
\hline \multicolumn{2}{|c|}{ Gender } & \multicolumn{2}{|l|}{ Group } & \multirow{2}{*}{ Total } \\
\cline { 3 - 5 } \multicolumn{2}{|c|}{$\begin{array}{l}\text { Group } \\
\text { A }\end{array}$} & $\begin{array}{l}\text { Group } \\
\text { B }\end{array}$ & \\
\hline \multirow{2}{*}{ Male } & Count & 8 & 8 & 16 \\
\cline { 3 - 5 } & $\begin{array}{l}\text { \% within } \\
\text { Group }\end{array}$ & $28.6 \%$ & $29.6 \%$ & $29.1 \%$ \\
\hline \multirow{2}{*}{ Female } & Count & 20 & 19 & 39 \\
\cline { 2 - 5 } & $\begin{array}{l}\text { \% within } \\
\text { Group }\end{array}$ & $71.4 \%$ & $70.4 \%$ & $70.9 \%$ \\
\hline \multirow{2}{*}{ Total } & Count & 28 & 27 & 55 \\
\cline { 2 - 5 } & $\begin{array}{l}\text { \% within } \\
\text { Group }\end{array}$ & $100.0 \%$ & $100.0 \%$ & $100.0 \%$ \\
\hline
\end{tabular}

Chi square value $=0.007, \mathrm{p}=0.913$

Group A: NSAIDs+ ADLs+ Ultrasound therapy(UST)+ Thumb spica splint

Group B: NSAIDs+ ADLs+ Ultrasound therapy(UST)

Pattern of socioeconomic status: Socioeconomic status was found different in both groups where poor was $43.6 \%$, middle class was $38.2 \%$ and rich was $18.2 \%$.

Table-2: Socioeconomic status

\begin{tabular}{|c|c|c|c|c|c|}
\hline \multicolumn{3}{|l|}{ Socioeconomic Status } & \multicolumn{2}{|l|}{ Group } & \multirow[t]{2}{*}{ Total } \\
\hline & & & Group A & Group B & \\
\hline \multirow[t]{6}{*}{ Socio economic condition } & \multirow[t]{2}{*}{ Poor } & Count & 12 & 12 & 24 \\
\hline & & $\%$ within Group & $42.9 \%$ & $44.4 \%$ & $43.6 \%$ \\
\hline & \multirow[t]{2}{*}{ Middle class } & Count & 10 & 11 & 21 \\
\hline & & $\%$ within Group & $35.7 \%$ & $40.7 \%$ & $38.2 \%$ \\
\hline & \multirow[t]{2}{*}{ Rich } & Count & 6 & 4 & 10 \\
\hline & & $\%$ within Group & $21.4 \%$ & $14.8 \%$ & $18.2 \%$ \\
\hline \multirow{2}{*}{\multicolumn{2}{|c|}{ Total }} & Count & 28 & 27 & 55 \\
\hline & & $\%$ within Group & $100.0 \%$ & $100.0 \%$ & $100.0 \%$ \\
\hline
\end{tabular}

Chi square value $=0.430, p=0.807$

Group A: NSAIDs+ ADLs+ Ultrasound therapy

Group B: NSAIDs+ ADLs+ Ultrasound therapy (UST) (UST)+ Thumb spica splint 
Table-4: Distribution of site of pain

\begin{tabular}{|l|l|l|l|l|}
\hline \multicolumn{2}{|l}{ Site of pain } & Group & \multirow{2}{*}{ Total } \\
\cline { 3 - 5 } \multicolumn{2}{|c|}{} & Group A & Group B & \\
\hline \multirow{3}{*}{ Localized } & Count & 25 & 26 & 51 \\
\cline { 2 - 5 } & $\%$ within Group & $89.3 \%$ & $96.3 \%$ & $92.7 \%$ \\
\cline { 2 - 5 } & Radiation present & Count & 1 & 4 \\
\cline { 2 - 5 } & \% within Group & $10.7 \%$ & $3.7 \%$ & $7.3 \%$ \\
\hline \multirow{2}{*}{ Total } & Count & 28 & 27 & 55 \\
\cline { 2 - 5 } & $\%$ within Group & $100.0 \%$ & $100.0 \%$ & $100.0 \%$ \\
\hline
\end{tabular}

Chi square value $=1.002, \mathrm{p}=0.317$

Group A: NSAIDs+ ADLs+ Ultrasound therapy (UST)+ Thumb spica splint

Group B: NSAIDs+ ADLs+ Ultrasound therapy (UST)
Characters of pain of the study subjects: Most of the patients in both groups had constant and intermittent type of pain $(47.5 \%$ and $45.5 \%)$ other types were sharp and dull.

Table-6: Characters of pain

\begin{tabular}{|c|c|c|c|c|c|}
\hline \multirow{2}{*}{\multicolumn{3}{|c|}{ Characters }} & \multicolumn{2}{|l|}{ Group } & \multirow{3}{*}{\begin{tabular}{|l|} 
Total \\
26 \\
\end{tabular}} \\
\hline & & & Group A & Group B & \\
\hline \multirow[t]{8}{*}{ Characters of pain } & \multirow[t]{2}{*}{ Constant } & Count & 12 & 14 & \\
\hline & & $\%$ within Group & $42.9 \%$ & $51.9 \%$ & $47.3 \%$ \\
\hline & \multirow[t]{2}{*}{ Intermittent } & Count & 12 & 13 & 25 \\
\hline & & $\%$ within Group & $42.9 \%$ & $48.1 \%$ & $45.5 \%$ \\
\hline & \multirow[t]{2}{*}{ Sharp } & Count & 2 & 0 & 2 \\
\hline & & $\%$ within Group & $7.1 \%$ & $0.0 \%$ & $3.6 \%$ \\
\hline & \multirow[t]{2}{*}{ Dull } & Count & 2 & 0 & 2 \\
\hline & & $\%$ within Group & $7.1 \%$ & $0.0 \%$ & $3.6 \%$ \\
\hline \multirow{2}{*}{\multicolumn{2}{|c|}{ Total }} & Count & 28 & 27 & 55 \\
\hline & & $\%$ within Group & $100.0 \%$ & $100.0 \%$ & $100.0 \%$ \\
\hline
\end{tabular}

Group A: NSAIDs+ ADLs+ Ultrasound therapy (UST)+ Thumb spica splint

Group B: NSAIDs+ ADLs+ Ultrasound therapy (UST)
Pattern of diagnostic tests in both groups: Out of 55 total patients 54(98.2\%) had Finkelstein test positive where as Hitch hiker sign was positive among $87.3 \%$ of patients in both groups

Table-8a: Finkelstein test

\begin{tabular}{|c|c|c|c|c|}
\hline \multirow{2}{*}{\multicolumn{2}{|c|}{ Finkelstein test }} & \multicolumn{2}{|l|}{ Group } & \multirow[t]{2}{*}{ Total } \\
\hline & & Group A & Group B & \\
\hline \multirow[t]{2}{*}{ Positive } & Count & 27 & 27 & 54 \\
\hline & $\%$ within Group & $96.4 \%$ & $100.0 \%$ & $98.2 \%$ \\
\hline \multirow[t]{2}{*}{ Negative } & Count & 1 & 0 & 1 \\
\hline & $\%$ within Group & $3.6 \%$ & $0.0 \%$ & $1.8 \%$ \\
\hline \multirow[t]{2}{*}{ Total } & Count & 28 & 27 & 55 \\
\hline & $\%$ within Group & $100.0 \%$ & $100.0 \%$ & $100.0 \%$ \\
\hline
\end{tabular}

Table-8b: Hitch hiker sign

\begin{tabular}{|c|c|c|c|c|}
\hline \multirow{2}{*}{\multicolumn{2}{|c|}{ Hitch hiker sign }} & \multicolumn{2}{|l|}{ Group } & \multirow[t]{2}{*}{ Total } \\
\hline & & Group A & Group B & \\
\hline \multirow[t]{2}{*}{ Positive } & Count & 24 & 24 & 48 \\
\hline & $\%$ within Group & $85.7 \%$ & $88.9 \%$ & $87.3 \%$ \\
\hline \multirow[t]{2}{*}{ Negative } & Count & 4 & 3 & 7 \\
\hline & $\%$ within Group & $14.3 \%$ & $11.1 \%$ & $12.7 \%$ \\
\hline \multirow[t]{2}{*}{ Total } & Count & 28 & 27 & 55 \\
\hline & $\%$ within Group & $100.0 \%$ & $100.0 \%$ & $100.0 \%$ \\
\hline
\end{tabular}


GroupA: NSAIDs+ ADLs+ Ultrasound therapy(UST)+ Thumb spica splint

Group B: NSAIDs+ ADLs+ Ultrasound therapy(UST)
Analysis of patient rated wrist evaluation (PRWE) at different follow up data in both group: No significant difference between Group A and Group B was found at different weeks of follow up(P>0.05) regarding PRWE.

Table-11: PRWE evaluation

\begin{tabular}{|l|l|l|l|l|l|}
\hline \multicolumn{2}{|l}{ Group } & N & Mean & Std. Deviation & P value \\
\hline W0 PRWE & Group A & 28 & 60.29 & 9.854 & 0.525 \\
\cline { 2 - 7 } & Group B & 27 & 58.81 & 6.867 & \\
\hline \multirow{3}{*}{ W1 PRWE } & Group A & 28 & 63.43 & 9.442 & 0.126 \\
\cline { 2 - 7 } & Group B & 27 & 59.48 & 9.391 & \\
\hline W2 PRWE & Group A & 28 & 63.93 & 9.165 & 0.740 \\
\cline { 2 - 7 } & Group B & 27 & 59.56 & 8.635 & 0.345 \\
\hline W3 PRWE & Group A & 28 & 61.00 & 11.399 & 0.472 \\
\cline { 2 - 7 } & Group B & 27 & 58.37 & 8.876 & \\
\hline W4 PRWE & Group A & 28 & 58.86 & 13.148 & 0.506 \\
\cline { 2 - 7 } & Group B & 27 & 56.67 & 8.788 & \\
\hline W5 PRWE & Group A & 28 & 52.29 & 15.258 & \\
\cline { 2 - 7 } & Group B & 27 & 54.67 & 10.598 & \\
\hline W6 PRWE & Group A & 28 & 45.43 & 15.709 & \\
\cline { 2 - 6 } & Group B & 27 & 52.67 & 12.153 & \\
\hline
\end{tabular}

PRWE: Patient rated wrist evaluation

Group A: NSAIDs+ ADLs+ Ultrasound therapy (UST)+ Thumb spica splint

Group B: NSAIDs+ ADLs+ Ultrasound therapy (UST)

\section{DISCUSSION}

In the present study gender in both groups male and female were matched and female to male ratio was $2.43: 1$. Female $(70.9 \%)$ were more affected than male $(29.1 \%)$. The incidence of de Quervain's is not known in primary care in Bangladesh, but the prevalence has been reported in the general population in the UK as $0.5 \%$ in men and $1.3 \%$ in women [13]. Here in the present study female were found to have affected more than male.

Socioeconomic status was found different in both groups where poor was $43.6 \%$, middle class was $38.2 \%$ and rich was $18.2 \%$. Here sampling were consecutive and only those patients were taken who visited the OPD of $\mathrm{CMCH}$. So this socioeconomic scenario may not represent the actual scenario of Bangladesh.

In the present study regarding wrist involvement right wrist were involved more in Group B than Group A (81.5\% vs 50. 0\%). There were some patients who had both wrist involvement (10.9\%). There were $92.7 \%$ patients who had localized pain and only $7.3 \%$ had radiation. Most of the pain in the evening $(56.4 \%)$ and rest had pain at night (43.6\%).

Most of the patients in both groups had constant and intermittent type of pain $(47.5 \%$ and $45.5 \%$ ) other types were sharp and dull. All patients in both groups had some aggravating factor but relieving factors were less $(45.45 \%)$. It has been reported that
$8.3 \%$ of patients present with upper extremity conditions as their chief complaint in chiropractic practices. Out of 55 total patients 54(98.2\%) had Finkelstein test positive whereas Hitch hiker sign was positive among $87.3 \%$ of patients in both groups. Diagnosis is usually concluded by a positive Finkelstein's test (which causes a reproduction of pain at the radial styloid), as well as the presence of a tender nodule over the radial styloid [14-16].

No significant difference between Group A and Group B was found at different weeks of follow-up $(\mathrm{P}>0.05)$ regarding PRWE. So it can be said that group A patients who were treated along with thumb spica splint had better outcome in reduction of pain and day to day activity.

\section{CONCLUSION}

De Quervain's tenosynovitis is often observed on repetitive flexion of the thumb. In the clinical setting, the conservative treatment is usually an applied thumb spica splint to immobilize the thumb in addition to other conventional treatment. These study shown that, the use of thumb spica splint in addition to other conventional treatment reduce the morbidity,pain relief and improve hand functions of the patient.

\section{REFERENCES}

1. Katana B, Jaganjac A, Bojičić S, Hadžiomerović AM, Pecar M, Kaljić E, Muftić M. Effectiveness of physical treatment at De Quervain' $\mathrm{s}$ disease. Journal of Health Sciences. 2012 Apr 15;2(1):804 
2. Papa JA. Conservative management of De Quervain's stenosing tenosynovitis: a case report. J Can Chiropor Assoc. 2012 June; 56(2):112-20

3. Veluthamaningal CP, Winters JC, Groenier KH, de Jong BM. Randomised controlled trial of local corticosteroid injections for de Quervain's tenosynovitis in general practice. BMC Musculoskelet disord. 2009;10:131

4. Hassan MK, Rahman MH, Sobhan F, Shoma FK, Walid CM. Role of Ultrasound In The Management of De'Quervain's Disease. Medicine Today. 2012; 24(01):31-35

5. Kaux JF, Forthomme B, Goff CL, Crielaard JM, Croisier JL. Current opinion on tendinopathy. Journal of Sports Science and Medicine. 2011; 10:238-53

6. Foye PM. Physical Medicine and Rehabilitation for De Quervain Tenosynovitis Clinical Presentation. 2012. Available at: http://emedicine.medscape.com/article/327453

7. Das KP,Talukdar DC, Chowdhury RM, Islam A, Datta NK, Shoma FK et al. Patients satisfaction of surgery for resistant cases of de Quervain's disease. J Dhaka Med Coll. 2011; 20(2):146-52.

8. Anderson M, Tichenor CJ. A Patient with De Quervain's Tenosynovitis: A Case Report Using an Australian Approach to Manual Therapy. Phys ther. 1994; 74:314-26.

9. Bengtson KA, Brault JS, Gerber LH. Hand disorders. In: Frontera WR, Delisa JA, Gans BM, Walsh NE, Robinson LR et al. Delisa's Physical
Medicine \& Rehabilitation Principles and Practice. 5th ed. USA: Lippincott Williams\& Wilkins; 2010: 941-42.

10. Jongprasitkul H, Suputtitada A, Kitisomprayoonkul W, Pintawiruj K. Elastic bandage vs. neoprene thumb stabilizer splint in acute De Quervain's tenosynovitis. Asian Biomedicine. 2011 April;5(2):263-67.

11. Swezey RL. Rehabilitation in Arthritis and Allied conditions. In: Kottke FJ, Lehmann JF. Krusen's Hand book of Physical Medicine and Rehabilitation.4th ed. USA: Saundars; 1990:694.

12. Brotzman SB, Meyers SJ, Phillips K. De Quervain's Tenosynovitis. In: Brotz SB, Wilk KE. Clinical Orthopaedic Rehabilitation. 2nd ed. USA: Mosby; 2003:73.

13. Crawford JO, Laiou E. Conservative treatment of work-related upper limb disorders-a review. Occup Med. 2007; 57(1):4-17.

14. Avci S, Yilmaz C, Sayli U. Comparison of nonsurgical treatment measures for de Quervain's disease of pregnancy and lactation. J Hand Surg. 2002; 27A(2):322-324.

15. National Board of Chiropractic Examiners. Practice analysis of chiropractic. Chapter 8: Patient conditions. 2010. pp. 95-120. http://nbce.org/publication/job-analysis.html.

16. Skoff HD. Postpartum/newborn" de Quervain's tenosynovitis of the wrist. Am J Orthop. 2001; 30(5):428-30. 